\title{
Endings and Beginnings
}

\author{
Elizabeth M. Dolan ${ }^{1}$
}

Published online: 22 October 2018

(c) Springer Science+Business Media, LLC, part of Springer Nature 2018

I will be retiring as JFEI's Editor in Chief at the end of the calendar year. The new Editor in Chief is Dr. Joyce Serido from the University of Minnesota. Dr. Serido and I have been in close communication since her appointment, and we are both hoping that the transition in leadership will be seamless.

I have enjoyed my 7 years as Editor and am proud of two major milestones reached by the journal.

When I became Editor, we were getting just about 100 manuscripts a year. I had hoped that we would surpass the 150 mark this year-we did not quite make it last year. As of the time that I am writing this (mid-October), 170 manuscripts have been submitted to JFEI. So, with more than 2 months remaining in the year, the total may well be close to 200 manuscripts.

The growth in the number of submissions is primarily due to the quality of papers that have been published in JFEI (more about that below). But the very recent increase in the number of manuscripts being submitted to JFEI is largely due to the journal being accepted by the Social Sciences Citation Index (SSCI) to receive an impact factor. We thought we would get the first impact factor in Spring 2019, but we already getting notices about JFEI's impact factor (0.98 for September 2018). I have every expectation that this number will increase substantially over time.

The quality of the journal depends on the quality of the manuscripts published. I want to thank the authors who think of JFEI when trying to decide on a journal to which to submit their manuscripts. The reviewers, however, are the heart and soul of the publishing process. Without excellent, dedicated reviewers whose comments help the authors to polish their manuscripts, JFEI would not have been accepted by the SSCI for an impact factor. Thank you all who do such a wonderful job of reviewing for JFEI. I also want to mention the dedication of the Associate Editors, both current and past, who help with the review process. You have made my responsibilities so much easier by doing such a good job with the manuscripts assigned to you. I also want to thank the Springer staff, both current and past, who have made the mechanics of editing the journal proceed smoothly and easily.

I know I am handing the management of JFEI over to very capable hands. I will, however, miss checking the JFEI email every morning and reading the new manuscript submissions, but I am sure I will find other things to keep myself "entertained and out of mischief."

Thank you all, again, for a lovely and productive 7 years. As I say good-bye, I hope you all will greet the incoming JFEI Editor in Chief, Dr. Joyce Serido, warmly and make her time as Editor as rewarding as mine has been.

Elizabeth M. Dolan, Ph.D.

Elizabeth M. Dolan

1 Dover, USA 